\title{
Assessment of energy efficiency and sustainability scenarios in the transport system
}

\author{
Elena López • Andrés Monzón • Paul C. Pfaffenbichler
}

Received: 29 April 2011 / Accepted: 3 November 2011 /Published online: 27 November 2011

(C) The Author(s) 2011. This article is published with open access at SpringerLink.com

\begin{abstract}
Background Energy Policy is one of the main drivers of Transport Policy. A number of strategies to reduce current energy consumption trends in the transport sector have been designed over the last decades. They include fuel taxes, more efficient technologies and changing travel behavior through demand regulation. But energy market has a high degree of uncertainty and the effectiveness of those policy options should be assessed.

Methods A scenario based assessment methodology has been developed in the frame of the EU project STEPS. It provides an integrated view of Energy efficiency, environment, social and competitiveness impacts of the different strategies. It has been applied at European level and to five specific Regions.

Concluding remarks The results are quite site specific dependent. However they show that regulation measures appear to be more effective than new technology investments. Higher energy prices could produce on their turn a deterioration of competitiveness and a threat for social goals.
\end{abstract}

\section{E. López $(\bowtie) \cdot$ A. Monzón}

TRANSyT-UPM, Centro de Investigación del Transporte,

Universidad Politécnica de Madrid,

Av. Profesor Aranguren,

28040 Madrid, España

e-mail: elopez@caminos.upm.es

A. Monzón

e-mail: andres.monzon@upm.es

P. C. Pfaffenbichler

Technische Universität Wien,

Institut für Verkehrsplanung und Verkehrstechnik,

Gußhausstr, 30/231,

1040 Wien, Austria

e-mail: paul.pfaffenbichler@tuwien.ac.at
Keywords Scenario assessment · Energy efficiency · Transport sustainability

\section{Introduction}

Over the past hundred years the widespread availability of fuel and its relative cheapness has given rise to an era of increased spatial dispersion of activities and high levels of mobility for those who could afford it. This growth has been accompanied and supported by a great expansion in the transport system. However, nowadays circumstances are changing. On the one hand, serious concerns over the future availability of the required fuel quantities have fostered the use of energy sources other than petroleum, as well as a reduction in the energy consumption of the transport system; and on the other, there is a growing preoccupation with the environmental consequences of transport activity. The sustainability of the transport system is increasingly becoming a top-priority objective of public administrations at all levels.

At strategic levels, these policy objectives are mainly driven by international commitments to reducing greenhouse gas (GHG) emissions. At the local level, key policy concerns include reducing pollutants, particularly in urban centres [1], and an environmentally friendly development [2].

In response to these concerns, various international agencies such as the International Energy Agency [3], the International Panel on Climate Change [4], the United Nations [5] the Organization for Economic Cooperation and Development [6], and European organizations such as the European Environmental Agency [7] have proposed strategies to improve transport-related energy efficiency and reduce its adverse environmental effects. 
The policy measures featured in these strategies include a wide spectrum of initiatives which range from an increase in fuel taxes, market incentives to reduce barriers to the introduction of alternative technologies [8], the development of standards for fuel energy consumption, or even awareness campaigns. However, the uncertainty about the future development of oil prices and about the rate at which the new technologies will penetrate the markets combine to hamper the task of making an accurate prognosis as to the expected efficacy of these policy measures $[9,10]$.

There are also political, social and environmental issues to be considered when assessing which technologies should be encouraged and invested in. All new technologies involve technological risks, in conjunction with doubts about the energy, social and economic future [11]. In this climate of high uncertainty, scenario building [12] and backcasting techniques [13] are useful planning tools for both planners and decision makers.

This paper makes a contribution to the scientific literature in this field with the proposal of a methodology to assess transport and energy scenarios from the perspective of sustainability. The paper is structured as follows. Section 2 contains a review of the policy documents regulating energy and transport sectors. The research approach of the STEPS project is presented in Section 3. The scenario-building process and the assessment methodology are described in Section 4. Section 5 discusses the assessment results. Finally, conclusions and final remarks are included in Section 6.

\section{European policy context}

The increasing importance of the Energy and Transport sectors in the EU came to the fore in 1999, when the Commission created a specific Directorate-General for the management of Energy and Transport Policy. These two sectors share a number of key features [14]:

- they are essential to economic competitiveness;

- they contribute to social and territorial cohesion;

- each one is the subject of important public service missions guaranteeing all users and consumers, wherever they may be within the Union territory, equal access in equitable conditions to quality services at affordable prices;

- they require substantial infrastructure with quality, interconnected networks and the issue of investments is vital to each one;

- they are often organized on a monopolistic basis, and face similar problems when confronted with the integration of national markets and regulatory changes;
- both have a major impact on the quality of our environment and are subject to the same requirements in terms of safety and security;

- they each have a major international dimension.

In summary, the main objective is for energy and transport to contribute to sustainable development, making Europe both a homogenous area of economic development and an area where the environment, in the broadest sense of the term, is conserved. These have become part of the Energy Policy targets incorporated into the Treaty establishing a Constitution for Europe, in the Official Journal of the European Union [15].

Current activity in the fields of transport and energy is based on two major policy documents:

The white paper European Transport Policy for 2010: time to decide [16] followed by its Mid-term review [17]. The White Paper proposes four main priorities:

- adjusting the balance between the different modes of transport;

- implementing the trans-European transport network;

- placing the user at the heart of transport policy;

- managing the effects of transport globalisation.

The green paper Towards a European strategy for the security of energy supply [18], which establishes three major strategic priorities:

- controlling the increase in demand, identifying two priority sectors: transport and construction;

- managing dependence on supply, not in order to maximise the Union's energy autonomy, but to reduce the risks of dependence;

- ensuring that the internal energy market works efficiently.

Finally, the Community Guidelines for the development of the trans-European transport networks [19] include essential EU transport policy objectives. The following list is a selection of the relevant objectives in the context of this paper:

- ensure the sustainable mobility of persons and goods (...) under the best possible social and safety conditions, while helping to achieve the Community's objectives, particularly in regard to the environment and competition, and contribute to strengthening economic and social cohesion;

- be, insofar as possible, interoperable within modes of transport and encourage intermodality between the different modes of transport;

- cover the whole territory of the Member States of the Community so as to facilitate access in general, link island, landlocked and peripheral regions to the central regions and interlink without bottlenecks the major conurbations and regions of the Community. 


\section{Strategies under scarcity of energy supply: the steps project}

The future framework of the transport system is closely linked to energy supply. The recurrent crisis and even wars in certain areas where oil and gas are produced are issues of major concern. There is also alarm as to the environmental consequences of transport use. Several policy documents have highlighted the long-term impacts of different transport strategies [20].

It is therefore necessary to explore the potential effects of technological, socioeconomic and political drivers for changing present energy consumption patterns and trends [39].

During the last decade, a number of studies have been oriented to understanding the long-term impacts of transport policies on energy scenarios [21]. Ozan et al. [22] maintain that transport demand policies are more effective than measures for improving energy efficiency on rural roads. Aranda et al. [23] analyse the future impacts of renovating vehicle fleets and transferring demand from road to other modes. Rajan [24] finds that policies that focus only on technology and pricing are insufficient, and must be supplemented with long-term lifestyle and land-use changes.

This leads to the conclusion that forecasting energy scenarios is a complex issue. There are many drivers affecting energy efficiency, including transport costs and economic competitiveness, technology supply, social and behavioural changes. It is therefore necessary to develop dynamic tools to build long-term scenarios where all the factors can interact over time. This was the target of the STEPs project [39] where a number of scenarios were built to test the impact on energy consumption of alternative transport strategies at the European level. The first group of strategies involves technological improvements in alternative vehicle technologies and transportation fuels, with the aim of exploring their potential for changing the energy mix. The second group of strategies focuses on controlling transport demand, and includes taxation on fuel and car use and regulating urban development with emphasis on public transport use and node development.

\section{Assessment methodology}

\subsection{Outline of the STEPs methodology}

The scenarios are assessed using a multicriteria analysis (MCA) methodology, as outlined in Fig. 1. The procedure starts with two preliminary tasks. The first is to define the scenarios to be assessed, whose impacts will be computed using a set of models at a European and regional/local scale. Second, in order to select the list of assessment criteria, a review is made of the major energy and transport related policy documents at the European scale. Each criterion is then assigned a performance indicator, computed from the outputs of the models. The assessment matrix is built from these performance indicators, which are then transformed by means of an MCA procedure into an assessment score for each scenario; this score includes the definition of a common set of utility functions and criteria weights. The final step in the methodology is to test the consistency of the assessment results by means of a sensitivity analysis. Figure 1 shows an outline of the assessment procedure, while the assessment stages are described in subsections 4.2. to 4.5.

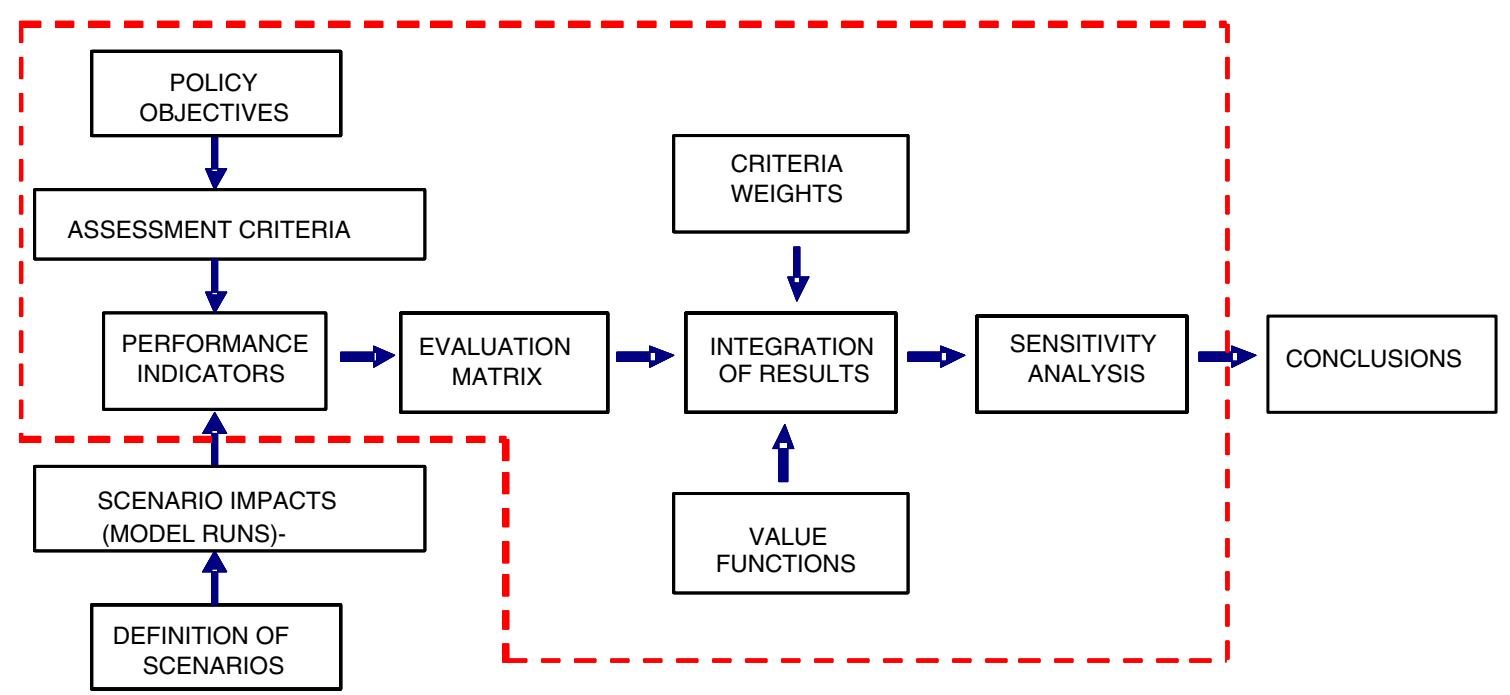

Fig. 1 Outline of the assessment methodology 


\subsection{Scenario definition}

Eight different main scenarios have been defined until the year 2030. The matrix defining the eight scenarios was built from the combination of two forecasts on future energy supply -the two rows- and four alternative policy strategies -the four columns-, as shown in Table 1.

First, from the point of view of energy availability, the scenarios are divided into two groups:

- Scenarios A, based on a generally accepted energy supply forecast, in which oil prices are assumed to increase $2 \%$ per year on average;

- Scenarios B, based on the scarcity of energy assumption, i.e. oil prices are projected to increase $7 \%$ per year on average.

The selection on these average annual increase rates was conducted based on the available forecasts provided by international energy related agencies, such as the IPCC, the IAE and the OECD.

Second, from a policy perspective, four contrasting policy strategies are considered:

- Scenarios -1: No policies alternative

- Scenarios 0: Business as usual alternative, where only a limited number of policy measures -consistent with the current direction of transport and energy policy- are assumed.

- Scenarios 1, concentrating on investments in technologies (i.e. improving energy efficiency, supporting innovative vehicles).

- Scenarios 2, focusing on demand regulation (i.e. reducing the need for travel, reducing trip lengths, shifting demand onto public modes, etc.)

\subsection{Scenario modelling}

Several modelling tools are used in order to simulate the scenarios on transport and energy supply and to provide quantitative responses as to the effects of these scenarios on

Table 1 Assessment scenarios

\begin{tabular}{lllll}
\hline & $\begin{array}{l}\text { No policies } \\
- \text { only fuel } \\
\text { price }\end{array}$ & $\begin{array}{l}\text { Business } \\
\text { as usual }\end{array}$ & $\begin{array}{l}\text { Technology } \\
\text { investments }\end{array}$ & $\begin{array}{l}\text { Demand } \\
\text { regulation }\end{array}$ \\
\hline $\begin{array}{c}\text { Generally-accepted } \\
\text { energy supply } \\
\text { forecast }\end{array}$ & A-1 & A0 & A1 & A2 \\
$\begin{array}{c}\text { Worst-case energy } \\
\text { supply forecast }\end{array}$ & B-1 & B0 & B1 & B2 \\
\hline
\end{tabular}

a range of aspects. These models can be classified into two main categories:

- models operating at the European level: the ASTRA system dynamics model [25], the SASI socio-economic model [26], and the POLES energy model [27] and

- models operating at the urban/regional level: the Dortmund model [28], South Tyrol and Helsinki MEPLAN models [29], Brussels IRIS model [30] and the Edinburgh MARS model [31].

The models cover a range of different methodologies. Although the ASTRA and SASI are both European models, they work with two different approaches. Based on a coarse geographical system, ASTRA is a system dynamics model where the input/output relationships between sectors play a major role in explaining the linkages between transport, economy and environment. SASI is a recursive (i.e. equilibrium-seeking) model aimed at analysing the impacts of infrastructures and other major changes in the transport system on local economies, in which these impacts are modelled using regional production functions including spatially disaggregate accessibility indicators. Therefore although both models reveal how changes in the transport side affect the economy, their response is given from two distinct perspectives.

Various differences can also be noted in the regional models. From the methodological standpoint, almost all models include a degree of interaction between land use and transport, albeit not in the same way (the Helsinki and the South Tyrol model share the same software and are more similar; the Dortmund and the Edinburgh model are built with different relationships). The local contexts are also different: the Brussels and Dortmund models focus on very densely populated metropolitan areas with millions of inhabitants; the Helsinki and Edinburgh models cover wider regions with a major city centre where most of the population live; finally, the study area in the South Tyrol model is the whole province, sparsely populated and where the largest city has no more than 100,000 inhabitants.

Each different model used for simulating the scenarios thus takes a different approach to considering the impacts of the policies; specific mechanisms that play a major role in one tool could be secondary in another and therefore give rise to different effects. A more detailed description of the models used in the project STEPS is beyond the scope of this paper. More technical information about the models and especially the issue of the consistency of the modelling results can be found in Fiorello et al. [39] and (STEPS consortium [32]).

\subsection{Definition of assessment criteria and indicators}

The list of criteria and the corresponding performance indicators for evaluating each scenario are defined based 
on the review of EU transport and energy policy documents $[7,14,16]$. The rationale for this proposed structure was the intention to assess both the performance of the transport and energy system, and its consequences from a social, environmental and economic perspective, following the threefold approach of the sustainability paradigm [33].

Four criteria categories were defined: energy, environment, social and competitiveness. The last one corresponds to the economic aspects of sustainability, but from the point of view of how the improvements in the transport sector will contribute to a more competitive general economy. This approach differs from the proposed for a number of researchers $[9,10,34,35]$ to assess the impact of specific transport policy measures and local scale projects. The proposed set of criteria and their corresponding performance indicators (see Table 2) are more strategic, intending to show long term market and economy trends. The selection of indicators has followed a consultation process among stakeholders participating in the STEPs project. They are possible outputs of the models applied in the project. They are designed to catch up the macro-level and long term impacts of general transport policies in the proposed scenarios.

\subsection{Integration of performance values}

In order to obtain integrated scores in each of the four categories, ${ }^{1}$ it is necessary to define both criteria weights and utility functions. The results have been determined following a MCA process. Criteria weights were defined by means of a targeted survey ${ }^{2}$ of experts, academics and stakeholders in the field of transport and energy, following a direct method (see [36]). Then, linear value functions were established in order to transform the values obtained in each indicator into a utility value (see Fig. 2). It was decided to use a common set of criteria weights and utility values in order to facilitate the interpretation and comparison of results. The last step in the MCA process was to apply the linear additive model, which multiplies the score of each indicator by its weight, and then aggregates these scores to obtain the utility value of a given scenario [37].

\footnotetext{
${ }^{1}$ No aggregation of the corresponding four scores has been made in STEPS, for two main reasons. The first is that none of the models provides performance indicators for all the indicators, and it is therefore not possible to compute a "strict" global social utility value for each scenario. The second reason is for the purpose of giving the decision-maker the final say on the best scenario, depending on the trade-offs between the -often conflicting- scores obtained in each of the aforementioned four criteria groups.

${ }^{2}$ The questionnaire was distributed mainly by e-mail through most European countries, including new accession members. Some responses were also collected in two specific workshops of the project in 2006.
}

Finally, a sensitivity analysis of assessment results to changes in criteria weights and utility functions allows checking the consistency of results.

\section{Analysis of results}

\subsection{Assessment framework}

In order to make any comparison among the scenarios, it is first necessary to define a reference scenario. In this case, scenario A-1 -no policies, and fuel price increase following observed past trends- was selected for this purpose. Thus in order to facilitate the interpretation of the results, in the following hypotheses the performance of each scenario is compared with the one obtained in scenario A-1:

- On the one hand, the effect of an increase in fuel prices is isolated if the reference scenario is assessed against scenario B-1.

- On the other hand, the effect of the different policy packages present in each scenario is more easily highlighted when the reference scenario is compared against policy scenarios with the same fuel price assumptions, i.e. $\mathrm{A} 0, \mathrm{~A} 1$ and $\mathrm{A} 2$.

A comparison of the reference scenario (Scenario A-1) with another scenario combining different fuel prices and the implementation of policy measures gives an idea of the overall effect obtained, although making it difficult to identify which part of the effect is caused by these factors.

Tables 3 and 4 included in this paper include both the comparison of qualitative scores of scenarios located in the same row and/or column of the reference scenario A-1, and diagonal comparisons (e.g. A-1 vs B1) which make additional contributions to the analysis. Complete assessment results for all the models and scenarios can be found in Fiorello et al. [39].

\subsection{Assessment results}

The comparison of assessment results across scenarios is aimed at investigating whether similarities appear in the direction of the predicted effect across models. A direct comparison of quantitative assessment scores across models would not provide any consistent conclusions, as -as detailed in previous sections- each model has its own specific features and does not provide indicators for the complete set of criteria categories. Hence, an overall qualitative comparison of the direction and magnitude of the effects is included in this section. This qualitative comparison is aimed at analyzing if there are similarities in 
Table 2 Assessment criteria and performance indicators

\begin{tabular}{|c|c|c|}
\hline Criteria categories & Sub-criteria & Base performance indicator \\
\hline Efficiency and security of energy supply & $\begin{array}{l}\text { Reducing total energy consumption } \\
\text { Reducing import dependence } \\
\text { Increasing\% of renewables } \\
\text { Reducing energy consumption per unit } \\
\text { of transport/economic activity }\end{array}$ & $\begin{array}{l}\text { Total energy consumption (toE) } \\
\% \text { of energy from imports } \\
\% \text { of energy from renewable sources } \\
\text { toE/trip } \\
\text { toE/GDP }\end{array}$ \\
\hline Environmental & $\begin{array}{l}\mathrm{PM} / \mathrm{NO}_{\mathrm{x}} \text { emissions } \\
\text { Traffic noise emissions }\end{array}$ & $\begin{array}{l}\mathrm{CO}_{2} / \text { pers-km, t-km } \\
\text { total } \mathrm{CO}_{2} \\
\mathrm{PM} / \mathrm{NO}_{\mathrm{x}} \text { emissions (urban/rural area) } \\
\text { Noise emitted (urban/rural area) }\end{array}$ \\
\hline Social & $\begin{array}{l}\text { Increasing transport safety } \\
\text { Improving equity }\end{array}$ & $\begin{array}{l}\text { Total deaths/injuries } \\
\text { Territorial cohesion indicators of accessibility, } \\
\text { GDP \& employment }\end{array}$ \\
\hline Competitiveness & $\begin{array}{l}\text { Changes in accessibility } \\
\text { Increasing regional GDP } \\
\text { Increasing employment rates } \\
\text { Decoupling transport and GDP growth }\end{array}$ & $\begin{array}{l}\% \text { change (each mode) } \\
\% \text { change in GDP } \\
\% \text { change in unemployment rates } \\
\text { (\%GDP growth- } \% \text { transport growth) }\end{array}$ \\
\hline
\end{tabular}

the assessment results for the wide range of different model assumptions and site characteristics. ${ }^{3}$

For this purpose, for each model, the performance score of each scenario was compared with that of the reference scenario (Scenario A-1). A qualitative scale has been developed in order to classify the corresponding changes in criteria categories according to their magnitude -in large, medium or slight- and direction -as an improvement or a decrease-, for the models that calculate the corresponding scores ${ }^{4}$ Table 3 includes this qualitative comparison for "Scenarios A", whereas Table 4 shows the comparison of "Scenarios B", as previously defined in Table 1. In both Tables 3 and 4, the comparison is carried out in reference to Scenario A-1.

Starting with the analysis of the effect of trend measures modelled in Scenario A0, it can be noted that all models are consistent with regard to the effect on energy criteria. The direction of the predicted effect is unanimously positive. Nevertheless the spread is rather wide, with the slightest changes corresponding to Edinburgh. ${ }^{5}$ The effect on the environment indicator is also positive for all models with the exception of Edinburgh, where its value decreases slightly. In social terms, the direction of the effect differs

\footnotetext{
${ }^{3}$ It should be noted that the policy measures making the difference between the do-nothing and the BAU scenario are not consistent among the different case study areas.

${ }^{4}$ If the model does not provide values for a given criteria category, the scale shows a "not applicable" (n.a.) result.

${ }^{5}$ The observed differences in the Edinburgh model runs are mainly due to the increased accessibility by bus predicted by the model.
}

slightly across the models. The results are negative in Edinburgh -medium value- and in South Tyrol -slight decrease, while a moderate positive increase in social criteria appear in the ASTRA, SASI, Dortmund and Helsinki models. In relation to competitiveness criteria, the models computing the corresponding indicators show a consistent deterioration.

Similar conclusions can be drawn from an analysis of the effects of technology investment measures (see Scenario A1 information in Table 3): in general terms, the performance of the three first criteria categories improves at the expense of a deterioration in their competitiveness. The exception is Edinburgh, where there is a slight deterioration in the social utility and a slight improvement in the competitiveness utility.

Similar results are obtained when demand regulation measures (Scenario A2) are tested against the reference scenario. All models coincide in predicting positive effects in energy, environmental and social aspects. The only exception is SASI with a slight reduction in its social score. In the competitiveness criteria category, the direction of the effect is the same across all models: demand regulation policy measures show a deterioration in economic performance, with severe utility reductions.

In order to test the consistency on the conclusions on the direction of the above effects when fuel price increases, a similar assessment methodology is applied to "Scenarios B", as Table 4 shows. Starting with Scenario "B-1", the analysis of the qualitative scale values shows the forecasted effect of a fuel price increase: in general terms, all the models predict an improvement in energy, environment and 
Fig. 2 Value Functions in the MCA procedure

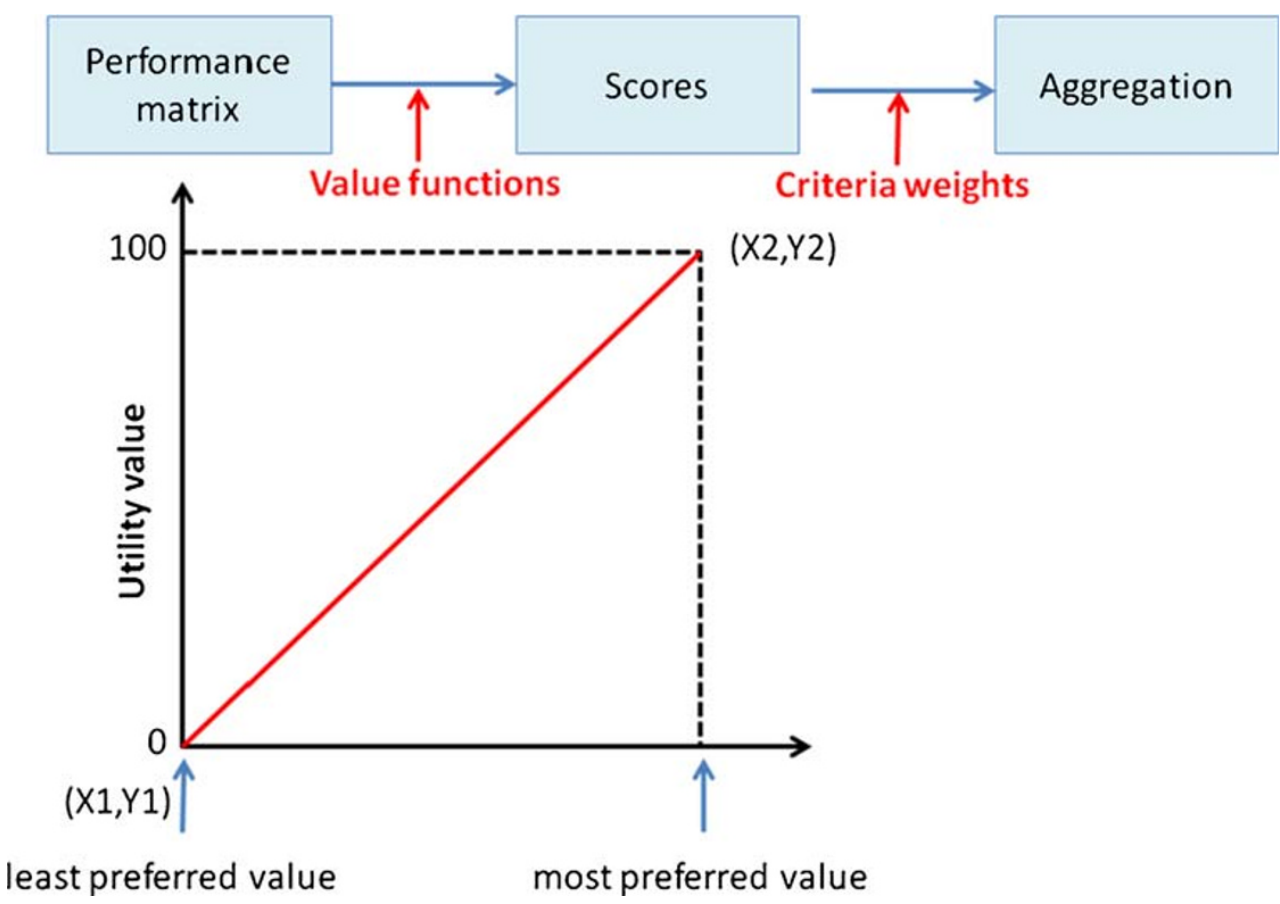

social categories along with lower competitiveness values as fuel prices increase. One slight exception is Edinburgh where social utility slightly decreases.

Similar conclusions can be drawn from an analysis of the resulting scores when assessing the combined effect of fuel price increases and BAU policies (scenario B0). The picture is similar when technology investment measures are implemented in combination with fuel price increases (scenario B1). Finally, demand management measures in a scenario with high fuel price (scenario B2) lead to both significant improvements in energy, environmental and social criteria, and important negative impacts on competitiveness across all models.

Finally, a sensitivity analysis was carried out in order to check the sensitivity of the results to changes in the criteria weights. In addition, the STEPS project included a meta-analysis of the results [38] in order to test the validity of the results across models. It is beyond the scope of this paper to show the complete results of both the sensitivity and meta-analyses. However, the conclusions extracted from both analyses show that, despite the significant heterogeneity across models, results are consistent in terms of the predicted performance of the defined transport and energy scenarios [38, 39].

\section{Conclusions}

In this context, the list below summarises some final remarks stemming from the assessment of the modelling results:
- In comparison with the do-nothing scenario, A-1 energy and environmental criteria improve when fuel prices (B scenarios), business as usual (0 scenarios), technology investment (1 scenarios) and demand regulation (2 scenarios) measures are implemented in all the models considered. The question of which of these four "packages of measures" has a stronger effect depends on the specific model and case study area under consideration.

- Demand regulation measures proved to be more effective than technology investments in terms of energy consumption and environmental criteria, i.e. a reduction in car use brought about by demand regulation measures exceeds the effect of more efficient technologies.

- The predicted effect in social criteria is not as straightforward. In general terms, safety indicators improve in all scenarios, whereas spatial equity indicators show both slight improvements and deteriorations, depending on the specific model and case study area considered. The predicted pattern of the spatial distribution of accessibility changes must be comprehensively analysed in order to draw significant conclusions on this topic.

- However, both fuel price increases and modelled policies give rise to higher transport costs, mobility constraints and reduced accessibility, which inevitably lead to a reduction in GDP and employment growth rates, i.e. they produce a deterioration in competitiveness criteria.

The trade-off between energy, environment and social criteria on the one hand, and competitiveness criteria on the 
Table 3 Assessment of "A" Scenarios (compared with A-1 Scenario)

\begin{tabular}{|c|c|c|c|c|c|c|c|c|}
\hline \multirow[t]{2}{*}{ Scenario } & \multirow[t]{2}{*}{ Criteria category } & \multicolumn{2}{|c|}{ European models } & \multicolumn{5}{|c|}{ Regional models } \\
\hline & & ASTRA & SASI & Brussels & Dortmund & Edingburgh & Helsinki & South Tyrol \\
\hline \multirow[t]{4}{*}{ Trend measures A0 } & Energy & +++ & n.a. & ++ & +++ & + & +++ & n.a. \\
\hline & Environment & ++ & n.a. & +++ & ++ & - & ++ & ++ \\
\hline & Social & ++ & ++ & n.a. & ++ & - & ++ & - \\
\hline & Competitiveness & - & - & n.a. & - & - & n.a. & - \\
\hline \multirow[t]{4}{*}{ Technology investments A1 } & Energy & +++ & n.a. & +++ & +++ & +++ & +++ & n.a. \\
\hline & Environment & +++ & n.a. & +++ & ++ & ++ & +++ & ++ \\
\hline & Social & ++ & ++ & n.a. & ++ & - & +++ & + \\
\hline & Competitiveness & - & - & n.a. & - & ++ & n.a. & - \\
\hline \multirow[t]{4}{*}{ Demand management A2 } & Energy & +++ & n.a. & +++ & +++ & ++ & +++ & n.a. \\
\hline & Environment & +++ & n.a. & +++ & +++ & +++ & +++ & +++ \\
\hline & Social & +++ & - & n.a. & +++ & +++ & +++ & + \\
\hline & Competitiveness & - & - & n.a. & - & - & n.a. & - \\
\hline
\end{tabular}

+++ Large improvement (above 50\%)

++ Medium improvement (from $10 \%$ to $50 \%$ )

+ Slight improvement (from $0 \%$ to $10 \%$ )

— Large decrease (below $-50 \%$ )

- Medium decrease (from $-50 \%$ to $-10 \%$ )

- Slight decrease (from $-10 \%$ to $0 \%$ )

n.a. Not applicable

Table 4 Assessment of "B" Scenarios (compared with A-1 Scenario)

\begin{tabular}{|c|c|c|c|c|c|c|c|c|}
\hline \multirow[t]{2}{*}{ Scenario } & \multirow[t]{2}{*}{ Criteria category } & \multicolumn{2}{|c|}{ European models } & \multicolumn{5}{|c|}{ Regional models } \\
\hline & & ASTRA & SASI & Brussels & Dortmund & Edingburgh & Helsinki & South Tyrol \\
\hline \multirow[t]{4}{*}{ No policies B1 } & Energy & +++ & n.a. & +++ & +++ & + & +++ & n.a. \\
\hline & Environment & ++ & n.a. & +++ & ++ & ++ & +++ & ++ \\
\hline & Social & ++ & + & n.a. & ++ & - & +++ & + \\
\hline & Competitiveness & - & - & n.a. & - & - & n.a. & - \\
\hline \multirow[t]{4}{*}{ Trend measures B0 } & Energy & +++ & n.a. & +++ & +++ & ++ & +++ & n.a. \\
\hline & Environment & +++ & n.a. & +++ & +++ & ++ & +++ & ++ \\
\hline & Social & ++ & + & n.a. & +++ & - & +++ & + \\
\hline & Competitiveness & - & - & n.a. & - & - & n.a. & - \\
\hline \multirow[t]{4}{*}{ Technology investments B1 } & Energy & +++ & n.a. & +++ & +++ & +++ & +++ & n.a. \\
\hline & Environment & +++ & n.a. & +++ & +++ & +++ & +++ & ++ \\
\hline & Social & ++ & ++ & n.a. & +++ & - & +++ & ++ \\
\hline & Competitiveness & - & - & n.a. & - & ++ & n.a. & - \\
\hline \multirow[t]{4}{*}{ Demand management B2 } & Energy & +++ & n.a. & +++ & +++ & +++ & +++ & n.a. \\
\hline & Environment & +++ & n.a. & +++ & +++ & +++ & +++ & +++ \\
\hline & Social & +++ & - & n.a. & +++ & +++ & +++ & + \\
\hline & Competitiveness & - & - & n.a. & - & - & n.a. & - \\
\hline
\end{tabular}

+++ Large improvement (above 50\%)

++ Medium improvement (from 10\% to $50 \%$ )

+ Slight improvement (from $0 \%$ to $10 \%$ )

— Large decrease (below $-50 \%$ )

- Medium decrease (from $-50 \%$ to $-10 \%$ )

- Slight decrease (from $-10 \%$ to $0 \%$ )

n.a. Not applicable 
other, is a key factor in the design of any integrated energy and transport policy. This conflict is present in the main EU policy documents $[7,17,18]$ : to what extent can economic growth be threatened in order to achieve environmental or social goals? The results of these scenario assessments provide the decision-maker with consistent and reliable information on the predicted effect of different sets of policy measures. This information will be a useful aid for selecting the most appropriate strategy, although political, social and numerous other factors beyond the scope of this research paper will also presumably drive the DMs' choice of the package of policy measures to implement.

Acknowledgments The research presented in this paper is part of the Coordination Action STEPS (Scenarios for the Transport System and Energy Supply and their Potential Effects), financed by the Sixth Framework Programme of the European Union.

Open Access This article is distributed under the terms of the Creative Commons Attribution License which permits any use, distribution and reproduction in any medium, provided the original author(s) and source are credited.

\section{References}

1. Carslaw DC, Beevers SD (2002) The efficacy of low emission zones in central London as a means of reducing nitrogen dioxide concentrations. Transp Res 7D:49-64

2. Stead D (2001) Transport intensity in Europe-indicators and trends. Transp Policy 8(1):29-46

3. IEA (1998) Energy efficiency initiative. Volume 1: energy policy analysis. IEA, Paris

4. IPCC (2001) Climate Change 2001. IPCC Third Assessment Report

5. UNDP (2000) World energy assessment: energy and the challenge of sustainability. United Nations Development Programme, New York

6. OECD (1998) Improving the environment through reducing subsidies, Part I: summary and policy conclusions, and Part II: analysis and overview of studies. OECD, Paris

7. EEA (2010) Towards a resource-efficient transport system, TERM 2009: indicators tracking transport and environment in the European Union. European Environment Agency, Technical report No 2/2010. Available at: http://www.eea. europa.eu/publications/towards-a-resource-efficient-transport-system

8. Steenberghen T, López E (2008) Overcoming barriers to the implementation of alternative fuels for road transport in Europe. J Clean Prod 16(5):577-590

9. Litman T (2005a) Efficient vehicles versus efficient transportation. Comparing transportation energy conservation strategies. Transp Policy 12(2):121-129

10. Litman T (2005b) Well measured: developing indicators for comprehensive and sustainable Transport Planning, VTIP; at www.vtpi.org/wellmeas.pdf

11. Goldman T, Gorham R (2006) Sustainable urban transport: four innovative directions. Technol Soc 28:261-273

12. OECD (2002) Policy instruments for achieving environmentally sustainable transport. OECD Publications, Paris, France

13. Geurs K, van Wee B (2004) Backcasting as a Tool for Sustainable Transport Policy Making: the Environmentally
Sustainable Transport. Netherlands Environmental Assessment Agency. The Netherlands, Delft University. EJTIR, 4, no. 1, pp. 47-69

14. EC (2004) Energy and transport: report 2000-2004. Office for Official Publications of the European Communities, Luxembourg

15. EU (2004) Treaty establishing a Constitution for Europe, Official Journal of the European Union, OJ 2004/C, 310/0, 16/12/2004 (Article III-256, Section 10: Energy, Title III, Part III)

16. EC (2001) White paper: European transport policy for 2010: time to decide. COM (2001) 370 final

17. EC (2006) Communication from the Commission to the Council and the European Parliament - Keep Europe moving - Sustainable mobility for our continent - Mid-term review of the European Commission's 2001 Transport White paper [COM (2006)314]

18. EC (2000) Green paper: towards a european strategy for the security of energy supply. COM (2000) 769 final

19. EC (2004b) Decision No 884/2004/EC of the European Parliament and of the Council amending Decision No 1692/96/EC on 21 April 2004 on Community guidelines for the development of the trans-European transport network

20. Banister D, Stead D, Steen P (2000) European transport policy and sustainable mobility. Spon Press, London, New York

21. Stead D, Banister D (2003) Transport policy scenario building. Transp Plan Technol 26(6):513-536

22. Ozan C, Haldenbilen S, Ceylan H (2011) Estimating emissions on vehicular traffic based on projected energy and transport demand on rural roads: policies for reducing air pollutant emissions and energy consumption. Energy Policy. doi:10.1016/j.enpol.2011.02.021

23. Aranda A, Valero A, Zabalza I, Scarpellini S, Llera E (2011) Energy 36:1916-1923

24. Rajan SCh (2006) Climate change dilemma: technology, social change or both? An examination of the long-term transport policy choices in the United States. Energy Policy 34:664-679

25. Fiorello D, Fermi F, Bielanska D (2010) The ASTRA model for strategic assessment of transport policies. Syst Dyn Rev 26:283290

26. Wegener M (2008) SASI model description. Working Paper 08/ 01. Dortmund: Spiekermann \& Wegener Urban and Regional Research

27. Russ P, Wiesenthal T, van Regemorter D, Ciscar JC (2007) Global climate policy scenarios for 2030 and beyond Analysis of Greenhouse Gas Emission Reduction Pathway Scenarios with the POLES and GEM-E3 models, Reference Report of the Joint Research Center of the European Commission, doi $10.2791 / 576$

28. Wegener M (1998) The IRPUD model: overview. http://irpud. raumplanung.uni-dortmund.de/irpud/pro/mod/mod e.htm

29. Echenique MH, Flowerdew AD, Hunt JD, Mayo TR, Skidmore IJ, Simmonds DC (1990) The MEPLAN models of Bilbao, Leeds and Dortmund. Transp Rev 10:309-322

30. Ministry of the Region of Brussels-Capital (1998) Plan IRIS Plan Régional de Déplacements, Regional Mobility Plan, Ministère de la Région de Bruxelles-Capitale. Bruxelles

31. Pfaffenbichler P, Emberger G, Shepherd S (2008) The integrated dynamic land use and transport model MARS. Netw Spat Econ 8 (2-3): 183-200

32. STEPS Consortium (2005) "Deliverable no. 4.1 - Modelling suite for scenarios simulations." STEPs (Scenarios for the Transport system and Energy supply and their Potential effectS), funded by the European Commission under the 6th Framework Programme. Retrieved September, 2011 from http://www.stepseu.com/reports.htm

33. López E, Monzón A (2010) Integration of sustainability issues in strategic transportation planning: a multi-criteria model for the 
assessment of transport infrastructure plans. Comput Aided Civ Infrastruct Eng 25(6):440-451

34. Castillo H, Pitfield DE (2010) ELASTIC-A methodological framework for identifying and selecting sustainable transport indicators. Transp Res D 15:179-188

35. Litman T (2008) Developing indicators for comprehensive and sustantinable transport planning. Transportation Research Record 2017, TRB, pp 10-15

36. Nijkamp P, Rietveld P, Voogd H (1990) Multicriteria evaluation in physical planning, North Holland, Amsterdam

37. De Montis A, de Toro P, Droste-Franke B, Omann I, Stagl S (2005) Assesing the quality of different MCDA methods. In:
Getzner M, Spash C, Stagl S (eds) Alternatives for environmental valuation. Routledge, Oxford, UK, pp 99-133

38. Spiekermann \& Wegener (2006) Comparability of scenario results. STEPs Technical Note S\&W STEPs 01. Dortmund. Spiekermann \& Wegener Urban and Regional Research. Retrieved September 2011 from http://www.spiekermann-wegener. de/pro/pdf/SuW_STEPs_03.pdf

39. Fiorello D, Huismans G, López E, Marques C, Steenberghen T, Wegener M, Zografos G (2006) Transport Strategies under the Scarcity of Energy Supply. STEPs Final Report, edited by A. Monzon and A. Nuijten. The Hague: Buck Consultants International. Retrieved September, 2011 from http://www.steps-eu.com/reports.htm 